Check for updates

NHS Providers

Cite this as: $B M J$ 2022;376:0547 http://dx.doi.org/10.1136/bmj.0547 Published: 2 March 2022

\section{Cracking delayed discharges will need local innovation and bold national action}

\author{
Hannah Hayes policy officer
}

Discharging people home or into community settings rapidly and safely after a stay in hospital has long been a significant shared challenge for the health and care system. The past few months have been no exception. The total number of medically fit patients waiting to be discharged has risen sharply during autumn and winter, reaching the highest level in mid-January, despite the best efforts of health and care colleagues, and despite NHS England and NHS Improvement setting a target in December 2021 for systems to halve delayed discharges. [1,2]

\section{What is the system up against?}

Delays in patient discharges occur when someone who is deemed medically fit to leave hospital is not discharged in a timely manner, with consequences for that individual and a ripple effect across the health and care sector. Although every case is different and there may be any number of reasons why an individual patient stays in hospital longer than necessary, in recent months, there have been three key factors involved: hospital admissions; staff absences; and operational pressures in the NHS and social care.

Trust leaders are most concerned by the pressures facing staff in both the health and social care sectors. On New Year's Eve, 1 in 10 NHS staff were absent, and social care providers were reporting workforce absences of between 5\%-10\%-unusually high rates largely driven by covid-19. [3] These absences are on top of high vacancy rates $-10.5 \%$ in the NHS and $8.2 \%$ in social care. [4] Staff shortages make timely discharge more important, and ironically more difficult to achieve, as trusts and social care colleagues may not have the skills mix available to support necessary assessments and make discharge arrangements.

NHS and social care providers have both struggled with capacity this winter. Hospitals are facing high levels of bed occupancy; the urgent and emergency care pathway is under significant strain; and community health services are at full stretch. These operational pressures make it difficult to facilitate patient discharges amidst competing priorities, care backlogs, and against increased demand, which is contributing to the challenge.

In addition to the pressures facing the NHS, trust leaders are concerned about capacity in the social care sector. In some areas, the impact of covid-19 outbreaks and staff shortages has forced some care homes to close their doors to new admissions, while some providers have had to hand back contracts to councils. [5] These pressures come at a time of increased demand for social care services, with a 15\% increase in the number of home care hours delivered and more than 400000 people awaiting assessments. [6] These growing demand pressures come in the context of years of underfunding of local government.

\section{Overcoming the challenges}

Trust leaders and their partners in social care are striving to provide the highest quality care in the most difficult of circumstances. Across the country, there are examples of trusts and social care partners working in new ways to make sure discharges happen as quickly as possible.

For example, Derbyshire Community Health Service NHS Foundation Trust has been supporting workforce capacity in the care home sector by sharing temporary bank staff with local authority run care homes to cover shifts. [7] The trust and local authority are now discussing how to develop service level agreements and share management costs in order to deliver this model at scale

Similarly, Sussex Community NHS Foundation Trust has worked with the local authority to create a care pathway that bridges hospital discharge and longer term care packages. [8] By temporarily providing care by a healthcare assistant while a package of domiciliary care is secured, the trust and the local authority has broken the link between hospital discharge and the complex task of setting up home based care for the long term.

Meanwhile other trusts are working with local authorities to explore whether providing care services themselves would benefit the local system. Northumbria Healthcare NHS Foundation Trust recently announced it would directly provide home care services, with a focus on increasing workforce capacity overall rather than disrupting the local market. [9]

Epsom and St Helier University Hospitals NHS Trust has also spent several years investing in its community services to support people to go home as soon as they are medically fit, which is better for patient outcomes and flow through the hospital. [10] Not only has this approach saved the trust money, but they have also managed to close four medical wards as more care is now delivered in the community.

\section{What do trusts and their partners need?}

Although these examples demonstrate how collaborative efforts to reduce delayed discharges can make progress, local action alone will not be enough to overcome the impacts of longstanding capacity, workforce, and funding shortages. 
The health and social care system urgently needs a national, joined up, fully funded workforce plan to ensure we have enough staff now and in the future.

Given the challenges across both sectors, we also need to ensure there is sufficient NHS funding across discharge pathways so that the principles of the scheme-of removing bureaucratic and financial barriers-can be retained after D2A funding ends next month.

The social care sector also urgently needs an appropriate, long term funding settlement and wider reform to ensure it can fully support its staff and meet the needs of local communities. Delayed discharges are just one symptom of the bigger challenge facing the sector, which will continue until social care is put on a sustainable footing.

In the meantime, integrated care systems will have a role to play in capitalising on the collaborative work undertaken throughout the pandemic. Bringing together system partners and sharing resources, as demonstrated in the case studies above, could be the start of local progress to the longstanding problem of delayed discharges-but this does not diminish the need for national support and government action to place the social care system on a sustainable footing.

Competing interests: none declared

Provenance and peer review: not commissioned, not peer reviewed

1 Providers NHS. NHS Winter watch 2021/22. Week 817 January - 23 January. https://nhsproviders.org/nhs-winter-watch-202122/week-8

2 NHS England and NHS Improvement. https:/www.england.nhs.uk/coronavirus/wp-content/uploads/sites/52/2021/12/C1487-letter-preparing-the-nhs-potential-impact-of-omicron-variant-andother-winter-pressures-v4.pdf

3 Independent. Care staff shortages mean vulnerable adults in 'lockdown by another name.' https://www.independent.co.uk/news/uk/covid-england-nhs-care-b1987220.html

4 NHS Digital. NHS Vacancy Statistics England April 2015 - September 2021 Experiment. https://digital.nhs.uk/data-and-information/publications/statistical/nhs-vacancies-survey/april2015-september-2021-experimental-statistics

5 The Guardian. Hundreds of UK care homes closing their doors as Omicron spreads. https://www.theguardian.com/society/2022/jan/05/hundreds-uk-care-homes-closing-doorscovid-omicron-spreads

6 ADASS Press Release. Snap Survey reveals a rapidly deteriorating picture of Social Care Services. https://www.adass.org.uk/snap-survey-nov21-rapidly-deteriorating-social-services

7 Case study- Derbyshire Community Health Service NHS Foundation Trust. https://nhsproviders.org/media/692653/case-study-derbyshire-community-health-services-nhsft_final.pdf

8 Case study- Sussex Community NHS Foundation Trust. https://nhsproviders.org/media/692654/case-study-sussex-community-nhs-foundation-trust_final.pdf

9 HSJ. Hospital trust launches as social care provider. https://www.hsj.co.uk/north-east/hospitaltrust-launches-as-social-care-provider/7031705.article

10 Community Network. Discharge to assess: the case for permanent funding. https://nhsproviders.org/media/691621/210614-discharge-to-assess-funding-briefing.pdf 